\title{
Eco-friendly dyeing of cotton fabric with waste tea leaves-based tannin natural dye
}

\author{
Adeel S. ${ }^{1}$, Anjum M.N. ${ }^{2}$, Ahmad M.N. ${ }^{2}$, Fazal-ur-Rehman ${ }^{2}$, Saif M.J. ${ }^{2}$, Azeem M. ${ }^{3}$, Hassan A. ${ }^{4}$, Imran M. ${ }^{2}$ and Amin N. ${ }^{2}$ \\ ${ }^{1}$ Department of Chemistry, Government College University Faisalabad 38000, Pakistan \\ ${ }^{2}$ Department of Applied Chemistry, Government College University Faisalabad 38000, Pakistan \\ ${ }^{3}$ Department of Botany, Government College University Faisalabad 38000, Pakistan \\ ${ }^{4}$ Department of Chemistry, Federal Urdu University of Arts, Science and Technology, Gulshan-e- Iqbal Campus, Karachi, Pakistan \\ Received: 21/10/2020, Accepted: 12/01/2021, Available online: 04/10/2021 \\ *to whom all correspondence should be addressed: e-mail: anjumccj@hotmail.com, \\ https://doi.org/10.30955/gnj.003456
}

Graphical abstract

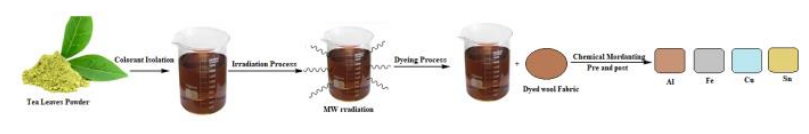

\begin{abstract}
Natural products have always been appreciated due to the awareness about environmental standards for global health by using green technologies in their isolation and extraction. Thereupon natural dyes have been used in all fields due to having ecofriendly, therapeutic and aesthetic nature. For the current study, microwave radiations (MW) have been used as a green extraction tool to explore the natural coloring potency of Tea leaves for the dyeing of cotton fabrics. For isolation of natural dye from tea leaves in aqueous and basic media MW irradiation for 1-6 min has been given and used to dye cotton fabric. It has been evaluated that an increase in color yield $(K / S)$ with the use of 6 min of microwave energy when basic extract of tea leaves was used to dye onto cotton fabric. It has been also revealed that in the case of the pre-mordanting method, $6 \%$ of $\mathrm{Cu}$ and $8 \%$ of $\mathrm{Fe}$ as a post mordanting method give the best fastness properties and the highest color yields. It is concluded that MW energy has an excellent ability for isolation of colorant from Tea leaves for dyeing of cotton fabric under reduced optimal dyeing conditions.
\end{abstract}

Keywords: Cotton, microwave radiation, mordants, natural dyes, tea leaves.

\section{Introduction}

The massive load wasted after frequent use of synthetic dyes into the aquatic system is one of the major environmental and human health issues (Bazgiret al., 2019; Kiran et al., 2018). The serious issue has lead the global village to more toward sustainable product. Natural dyes extracted from plants, animals and minerals are now being seen as promotion of green chemistry in textiles, food, cosmetics, and flavors, etc. (Ma et al., 2020; Otutuet al., 2019; Rajeswari, 2020). This is because natural dyes have no disposal problem, extracted under "low" conditions and have a lot of medicinal benefits (Athinarayanana et al., 2017). More than 1000 species are found as a source of natural colorant around the globe which is widely used in different fields now a days.

Due to increasing awareness about environmental safety, interest in natural dye and their applications also increasing (Haji and Naebe, 2020; Haji, 2019; Kiran et al., 2020; Tambiet al., 2021; Tayyab et al., 2020). Synthetic dyes are cost-effective and are widely available. Their availability decreases the interest in the art of natural dyeing (Kabiret al., 2020; Yan et al., 2019). Synthetic and natural dyes have particular importance in textile, leather, and in decentralization sector for special products (Phan et al., 2020). However, these dyes are hazardous but natural dyes are not toxic, have no allergic effects like synthetic dyes. In comparison the art of natural dyeing is an eco-friendly process because being easily biodegradable, these colorants have been blessed with excellent medicinal and sustainable properties (Haji and Naebe, 2020; Mahdi et al., 2021; Rather et al., 2019). Hence natural dyes defeat the deterioration of environment created by synthetic dyes and also used on broad hierarchy like a craftsman, printers,artisan furthermore on small extents such as cottage level and small-scale exporters and producer working with high valued eco-friendly manufacturing of textile (Adeel et al., 2021; Islam et al., 2018; Phan et al., 2020).

Many plant leaves act as source of natural dyes where tea leaves ( $C$. Sinensis) being an important member of Theaceae family (Fugre1 a) is mostly an ever green shrub cultivated in tropical and subtropical areas of China, Taiwan, India, and Japan. This plant extract (Figure 1b) has almost such potent metabolic compounds that have strong antimicrobial, anticancer, antioxidant activity and antifungal activityand widely used as medicine for the 
treatment of various diseases (Arkorful et al., 2020; Kumari et al., 2020). Its leaves are rich in polyphenolic compounds including flavonoids, Catechin, quercetin, Kaempherol, rutin, gallic acid, and phenolic acid, where catechin (Figure 1c) is the main coloring pigment that impart brown colour onto fabrics (Ren et al., 2019; Rho et al., 2019). Different fabrics are used in textiles, where cotton is extensively used. It is soft in nature having excellent absorbency, where its terminal hydroxyl groups present in cellulosic unit (Figure 1d) are used for bonding with colourant or mordants for shading.
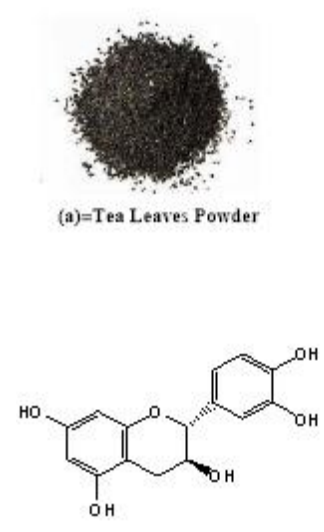

(c) = Erstechin
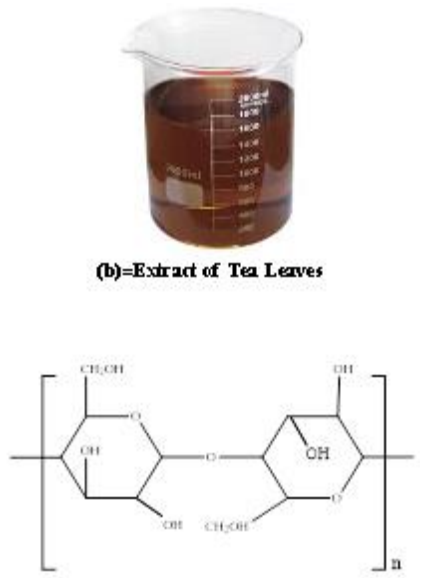

(d) Cotton Fabric
Figure 1. Tea Leaves Powder (a), Tea leaves extract (b), Catechin (c) and functional unit of Cotton (d).

To minimize the environmental related hazards with dyeing and extraction process, recently number of sustainable environment friendly process were introduced globally in textile industries (Haji and Rahimi, 2020; Hosseinnezhad et al., 2021). These processes includevarious radiation treatments such as plasma treatment (Haji, 2019; Haji, 2020; Haji and Naebe, 2020), microwave (Adeel et al., 2021; Kiran et al., 2020; Rabia et al., 2019), ultrasonic (Zia et al., 2019), gamma (Vujcic et al., 2019), and enzymatic pretreatment (Salem et al., 2020) for ecofriendly extraction and dyeing of textile fabrics.

Among all of these, treatments microwave is more efficient, rapid and environment friendly than other treatments (Adeel et al., 2021). The main advantage of microwave technique over conventional heat transfer is that microwave facilitates direct heating. Besides some advantages like reduction in cost, more compatibility, and use of smaller equipment (Adeel et al., 2020; Adeel et al., 2021). It also has some disadvantages such as it may be affected by topographical and weather conditions. The microwave heating technique was applied on different fibers and observed various difficulties in dyeing such as cotton dyeing decreases due to the presence of hydrophobic lipids on its surface. Unlike this, microwave, technique increases the dyeing rate of polyamide fibers and higher colorfastness on cotton fabrics. Results showed that fabric color yield strength can be increased by using microwave techniques in a short time (Adeel et al., 2021; Amin et al., 2020; Rabia et al., 2019). In view of these advantages, the current has been aimed to appraise the colouring potential of spent tea leaves for cotton dyeing under influence of microwave radiation and to enhance its color strength onto fabric after utilization of chemical mordants.

\section{Materials and methods}

\subsection{Sample preparation}

Waste of used tea leaves ( $C$. sinensis) (Figure $1 a-b)$ were collected from different places of Faisalabad. These wasted tea leaves were dried at room temperature and ground finely and sieved upto 20 mesh to obtain a powder of the tea leaves. Cotton fabric was obtained from Noor Fatima Fabrics Faisalabad Pakistan. The extract was prepared using the different mediumi.e.aqueous, basic extraction would be done by using the conventional method of extraction. The black tea waste powder was boiled for 40 minutes in aqueous and acidified organic medium and then extracted solution was filtered by using a fine cloth. Extracted solution and the cotton fabric was then irradiated using the microwave for the different interval of time 1-6 minutes.

\subsection{Dyeing procedure}

Dyeing of irradiated and un-irradiated extract and cotton was carried out by using four different conditions of RE/RC, $\mathrm{RE} / \mathrm{RC}, \mathrm{NRE} / \mathrm{RC}, \mathrm{RE} / \mathrm{NRC}$. The aqueous and basic extract was prepared than dyed with cotton fabric for 40 minutes by using the $M$ : C ratio of 1:30. The cotton fabric was dyed for a different condition. Irradiation of the samples was carried out using a microwave for the different intervals of time i.e. $1,2,3,4,5$ and 6 minutes. Aqueous extraction was carried out using $2 \mathrm{~g}$ of tea leaves powder with $100 \mathrm{~mL}$ of water at boiling in a conical flask. After processing, the crude material was filtered to get the required extract. In the same way basicextract was prepared using $2 \%$ Alkaline medium. After dyeing of irradiated and un-irradiated samples, the dyed samples were sent to the CIE Lab system for the determination of the color strength values and other fastness properties (Adeel et al., 2020; Adeel et al., 2021; Amin et al., 2020).

\subsection{Mordanting process}

After the optimization of the extraction and irradiation, the process of mordanting was done for the evaluation of the different shades. For this process different type of metal salts i.e. mordants were used. The mordants which were used are copper sulfate, ironsulfate, stannous chloride, and aluminum chloride. Pre and post mordanting would be done by using the different concentrations of the mordants described above. The mordants were used with a concentration line $2,4,6,8,10$ and $12 \%$.both pre and post mordanting was done and after completion of the mordanting process, themordanted fabrics were sent to the lab system for the evaluation of Color strength values and fastness properties (Adeel et al., 2020). The color strength value of each fabric was determined by using the spectra flash 600 at the department of chemistry government college university faisalabad.ISO-105 B02 was used to determine the colorfastness to light; ISO-105-C03 for washing fastness and ISO-105 X-12 method was used 
for the determination for the rubbing fastness would be used.

\section{Results and discussion}

The results are given in Figure 2( $a$ and b) show that microwave treatment has shown a significant effect on the dyeing of cotton with waste tea leaves using an aqueous extract. It is found that irradiated Basic extract (RE) for 6 min $\mathrm{MW}$ gives good Color strengthusing irradiated cotton (RC) Figure (1b). This is because microwave treatment modifies the cotton fabric physically by creating polarity which helps to make firm bonding with irradiated colorant of tea leaves (Adeel et al., 2019; Chen et al., 2017). For low time irradiation, physical modification is not possible whereas irradiation of low time to extract does not stimulate the colorant molecules to makeactive dyeing of cotton (Adeel et al., 2021; Hussaan et al., 2017; Kiran et al., 2018; Kiran et al., 2020).Comparatively, using aqueous extract, the irradiated extract ( $\mathrm{RE}=6 \mathrm{~min}$.) has shown good Color strength value onto un-irradiated cotton (NRC) Figure 1b. Again, the microwave treatment of cotton has a promising effect in the natural dyeing process using aqueous extract of waste tea leaves. Conclusively it is revealed that dyeing of irradiated cotton for (RC, 6min), $2 \%$ of basic tea extract (RE, 6min) should be used to get darker shades and high Color strength.

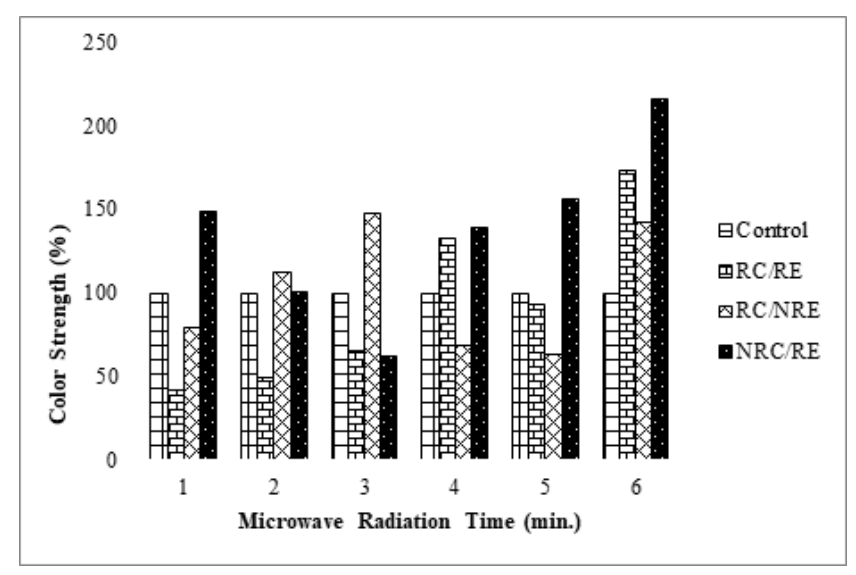

Figure 2a Effect of microwave radiation on dyeing using irradiated and non-irradiated cotton fabric and extract in aqueous media.

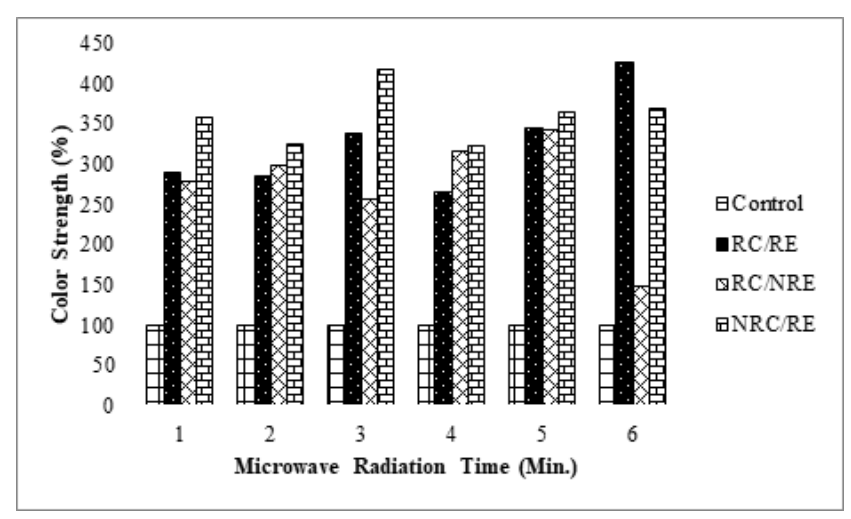

Figur $\mathbf{2 b}$ Effect of microwave radiation on dyeing using irradiated and non-irradiated cotton fabric and extract in alkali media.
Mordanting is a process that is essential for natural dyeing because it helps to get not only new shades but also to improve color strength and fastness properties. The results given in Figure (3a) for pre chemical mordanting and Figure (3b) for post chemical mordanting show that $4 \%$ of Alum, $6 \%$ of $\mathrm{Cu}, 6 \%$ of Fe and $6 \%$ of $\mathrm{Sn}$ as pre mordanting $4 \%$ of Alum, $6 \%$ of $\mathrm{Cu}, 8 \%$ of $\mathrm{Fe}$ and $10 \%$ of $\mathrm{Sn}$ as post mordanting gives darker shades, good color fastness properties. This is because in chemical mordanting these mordants concentrations form firm coordination covalentbondonto irradiated cotton which upon dyeing gives darker shades through metal dye complex (Adeel et al., 2021; Kiran et al., 2020; Rather et al., 2020; Zia et al., 2019).The proposed formation of metal dye complex onto fabric has been shown in Figure 4. Hence, overall, it is found that exposure of extract and cottonby microwaves for $6 \mathrm{~min}$. has not only given excellent colour yield but also reduced the amount of mordants used by giving good colour strength.

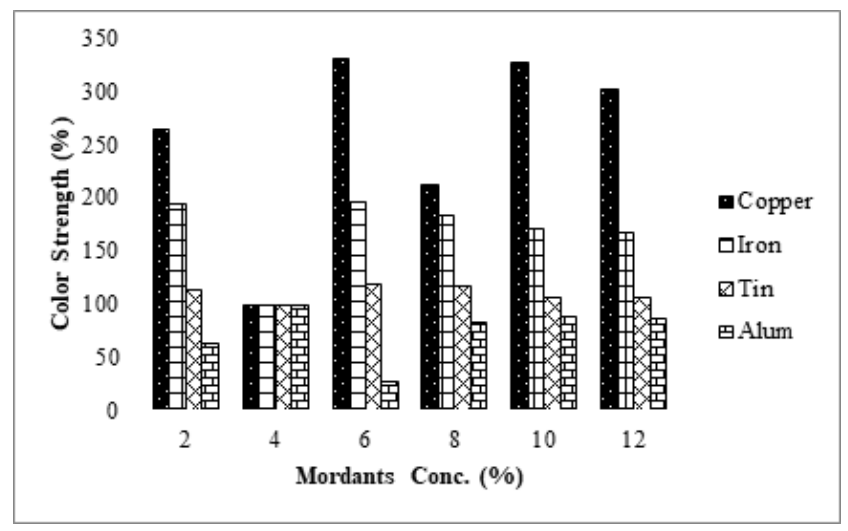

Figure 3a Effect of pre-Chemical mordanting on color strength of irradiated cotton dyed with irradiated basic extract of Tea

leaves.

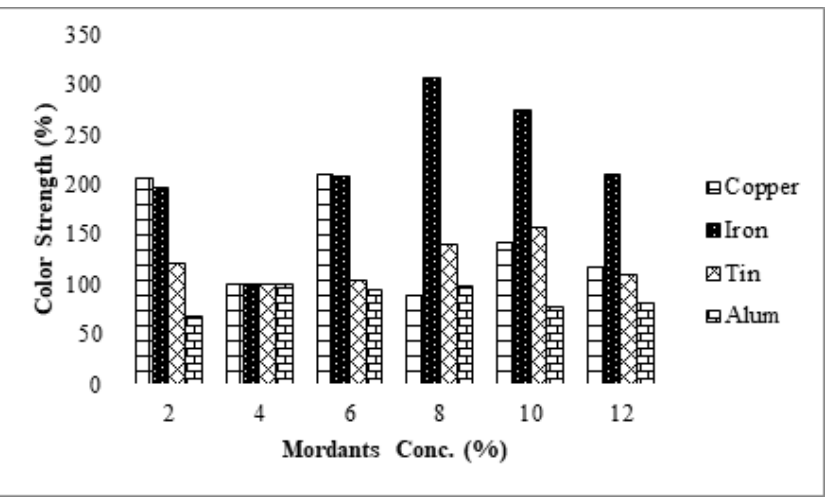

Figure $\mathbf{3 b}$ Effect of post-Chemical mordanting on color strength of irradiated cotton dyed with irradiated basic extract of Tea leaves.

\section{Conclusions}

Microwave radiation treatment for 6 minutes in the basic medium was acceptable to obtain good color strength. The recommendations show that catechin from tea leaves extracted in a basic medium by employing microwave treatment of 6 minutes has given better results of natural brown dye on irradiated cotton fabric. It has been also observed that excellent color strengths are obtained by using ecofriendly chemical mordants. Hence it is revealed that on accounts of economy, time, energy \& labor 
effectiveness, microwave radiations are used to add more value in sustainable extraction of natural colorant from tea leaves.

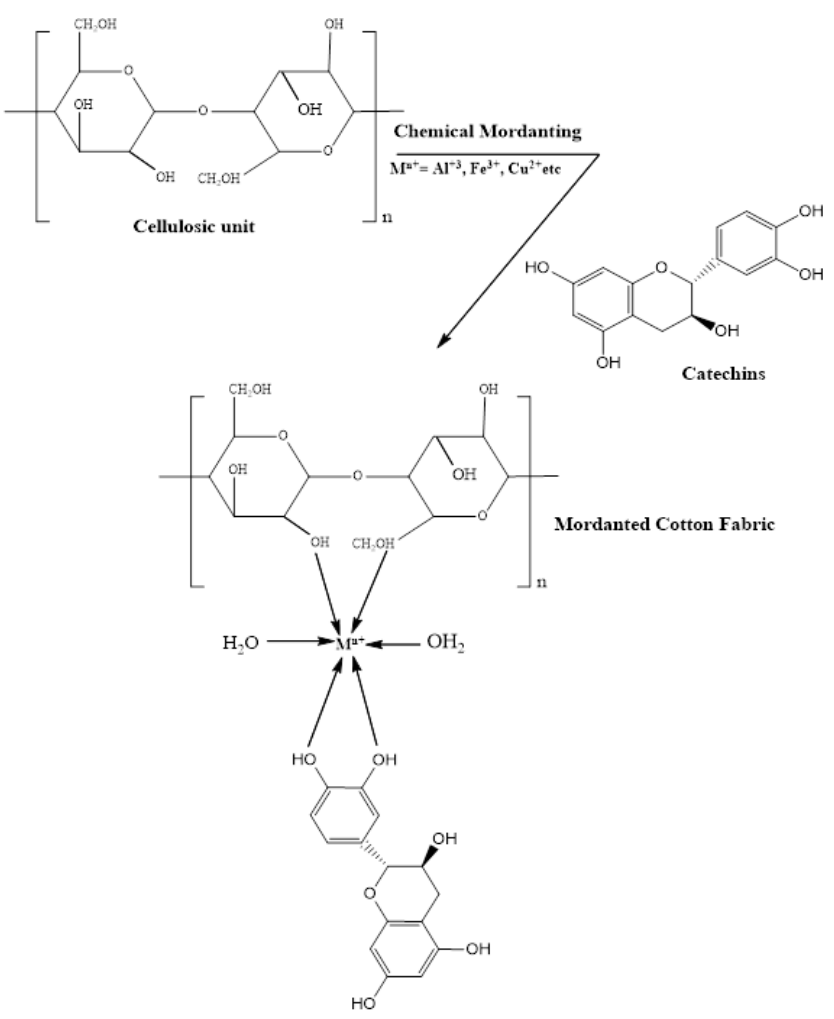

Figure 4 Proposed interaction of fabric functional site (Cellulose)with Colourant (Catechin) and Mordant $\left(\mathrm{M}^{\mathrm{n}+}\right)$.

\section{References}

Adeel S., Hussaan M., Rehman F.U., Habib N., Salman M., Naz S. and Akhtar N. (2019). Microwave-assisted sustainable dyeing of wool fabric using cochineal-based carminic acid as natural colorant, Journal of Natural Fibers, 16,1 026-1034.

Adeel S., Rehman F.U., Khosa K.M., Anum T., Shahid M., Zia M.K. and Zuber M. (2020). Microwave assisted appraisal of Neem bark based tannin natural dye and its application onto biomordanted cotton fabric, Iranian Journal of Chemistry and Chemical Engineering, 39(2), 159-170.

Adeel S., Rehman F.U., Zia K.M., Azeem M., Kiran S., Zuber M. and Qayyum M.A. (2021). Microwave-supported green dyeing of mordanted wool fabric with Arjun Bark Extracts, Journal of Natural Fibers, 18(1), 136-150.

Amin N., Adeel S., Ahamd T., Muneer M. and Haji A. (2020). Sustainable application of cochineal-based anthraquinone dye for the coloration of bio-mordanted silk fabric, Environmental Science and Pollution Research, 27(7), 68516860.

Arkorful E., Yu Y., Chen C., Lu L., Hu S., Yu H. and Chen X. (2020). Untargeted metabolomic analysis using UPLC-MS/MS identifies metabolites involved in shoot growth and development in pruned tea plants (Camellia sinensis L.) $\mathrm{O}$. Kuntz), Scientia Horticulturae, 264, 109164.

Athinarayanana G., Ranjitsingh A.J.A. and Padmalatha C. (2017). Toxicological studies of Caesalpiniasappan wood derived dye in Wister albino rats, Food Science and Human Wellness, 6(1), 34-38.

Bazgir A., Khorshidi A., Kamani H., Ashrafi S.D.and Naghipour D. (2019). Modeling of azo dyes adsorption on magnetic NiFe 2
O 4/RGO nanocomposite using response surface methodology, Journal of Environmental Health Science and Engineering, 17(2), 931-947.

Chen C., Zhang B., Huang Q., Fu X. and Liu R.H. (2017). Microwaveassisted extraction of polysaccharides from Moringa oleifera Lam. leaves: Characterization and hypoglycemic activity, Industrial Crops and Products, 100, 1-11.

Haji A. (2019), Dyeing of cotton fabric with natural dyes improved by mordants and plasma treatment, Progress in Color, Colorants and Coatings, 12(3), 191-201.

Haji A. and Rahimi M. (2020). RSM optimization of wool dyeing with Berberis Thunbergii DC leaves as a new source of natural dye, Journal of Natural Fibers, 1-14. https://www.tandfonline.com/doi/abs/10.1080/15440478.2 020.1821293.

Haji A. (2020). Natural dyeing of wool with henna and yarrow enhanced by plasma treatment and optimized with response surface methodology, The Journal of the Textile Institute, 111(4), 467-475.

Haji A. and Naebe M. (2020). Cleaner dyeing of textiles using plasma treatment and natural dyes: A review, Journal of Cleaner Production, 265, 121866.

Hosseinnezhad M., Gharanjig K., Jafari R. and Imani H. (2021). Green dyeing of woolen yarns with weld and madder natural dyes in the presences of biomordant, Progress in Color, Colorants and Coatings, 14(1), 35-45.

Hussaan M., Iqbal N., Adeel S., Azeem M., Javed M.T. and Raza A. (2017). Microwave-assisted enhancement of milkweed (Calotropis procera L.) leaves as an eco-friendly source of natural colorants for textile, Environmental Science and Pollution Research, 24(5), 5089-5094.

Islam S., Butola B.B. and Anasuya R. (2018). Chitosan polysaccharide as a renewable functional agent to develop antibacterial, antioxidant activity and colorful shades on wood dyed with tea extra polyphenols, International Journal of Biological Macromolecules, 120, 1999-2006.

Kabir S.M.M., Dhar A.K. and Bhattacharjee M. (2020). The use of natural Areca catechu dyes for silk and nylon and its halochromic effect, The Journal of The Textile Institute, 111(6), 882-889.

Kiran S., Adeel S., Rehman F.U., Gulzar T., Jannat M. and Zuber M. (2018). Ecofriendly dyeing of microwave treated cotton fabric using reactive violet H3R, Global Nest Journal, 21(1), 43-47.

Kiran S., Hassan A., Adeel S., Qayyum M.A., Yousaf M.S., Abdullah M. and Habib N. (2020). Green dyeing of microwave treated silk using coconut coir based tannin natural dye, IndustriaTextila, 71(3), 227-234.

Kumari M., Thakur S., Kumar A., Joshi R., Kumar P., Shankar R. and Kumar R. (2020). Regulation of color transition in purple tea (Camellia sinensis), Planta, 251(1), 35.

Ma X., Wei Y., Wang S., Zuo X. and Shen B. (2020). Sustainable ultrasound-assisted ultralow liquor ratio dyeing of cotton fabric with natural turmeric dye, Textile Research Journal, 90(5), 685-694.

Mahdi M.M., Tuj-Zohra F. and Ahmed S. (2021). Dyeing of shoe upper leather with extracted dye from Acacia nilotica plant bark-An eco-friendly initiative, Progress in Color, Colorants and Coatings, 14, 1-43.

Otutu J.O., Asiagwu A.K., Onyesom I.E., Ebigwai J.K. and Itoya P.O. (2019). Improving the efficiency of Nesogordonia papaeverifera (Danta) as a natural dye in textile making 
industry, Bulletin of the Chemical Society of Ethiopia, 33(3), 415-424.

Phan K., Van-Broeck E., Van-Speybroeck V., De-Clerck K., RaesK.and De-Meester S. (2020). The potential of anthocyanins from blueberries as a natural dye for cotton: A combined experimental and theoretical study, Dyes and Pigments, 176, 108180.

Rabia S.A., Mazhar H.P., Samad B.A. and Alvira A.A. (2019). An efficient ultrasonic and microwave assisted extraction of organic Henna dye for dyeing of synthetic polyester fabric for superior color strength properties, Industria Textila, 70(4), 303-308.

Rajeswari M.V. (2020). Application of natural dye from Babool bark on cotton fabric using mordants, International Journal of Scientific Development and Research, 5(2), 357-361.

Rather L.J., Shabbir M., Li Q. and Mohammad F. (2019). Coloration, UV Protective, and Antioxidant Finishing of Wool Fabric Via Natural Dye Extracts: Cleaner Production of Bioactive Textiles, Environmental Progress and Sustainable Energy, 38(5), 13187.

Rather L.J., Shabbir M., Mohammad F. and Li Q. (2020). Terminalia arjuna Dyed woolen yarn-effect of binary and ternary metal salt combinations: a greener route for production of ecofriendly textiles, Journal of Natural Fibers, 17(12), 16931705.

Ren Y., Fu R., Fang K., Chen W., Hao L., Xie R., and Shi Z. (2019). Dyeing cotton with tea extract based on in-situ polymerization: An innovative mechanism of coloring cellulose fibers by industrial crop pigments, Industrial Crops and Products, 142, 111863.

Rho T., Choi M.S., Jung M., Kil H.W., Hong Y.D.and Yoon K.D. (2019). Identification of fermented tea (Camellia sinensis) polyphenols and their inhibitory activities against amyloidbeta aggregation, Phytochemistry, 160, 11-18.

Salem M.Z., Ibrahim I.H., AliH.M. and Helmy H.M. (2020). Assessment of the use of natural extracted dyes and pancreatin enzyme for dyeing of four natural textiles: HPLC analysis of phytochemicals, Processes, 8(1), 59.

Tambi S., Mangal A., Singh N. and Sheikh J. (2021). Cleaner production of dyed and functional polyester using natural dyes vis-a-vis exploration of secondary shades, Progress in Color, Colorants and Coatings, 14, 121-128.

Tayyab N., Javeed A.A., Sayed R.Y., Mudassar A., Faisal R., Ahmad F. and Muhammad A. (2020). Dyeing and colour fastness of natural dye from Citrus aurantium on Lyocell fabric, IndustriaTextila, 71(4), 350-356.

Vujcic I., Masic S., Medic M., Milicevic B. and Dramicanin M. (2019). The influence of gamma irradiation on the color change of wool, linen, silk, and cotton fabrics used in cultural heritage artifacts, Radiation Physics and Chemistry, 156, 307-313.

Yan B., Yang M., Zhou Q., Xing T., Chen G., and Sheng J. (2019). Yellow pigment of Metarhiziumanisopliae and its application to the dyeing of fabrics, Coloration Technology, 135(4), 267-274.

Zia K.M., Adeel S., Aslam H., Khosa M.K.and Zuber M. (2019). Influence of ultrasonic radiation on extraction and green dyeing of mordanted cotton using neem bark extract, Journal of Industrial and Engineering Chemistry, 77, 317-332. 